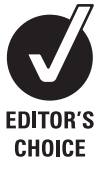

Ophthalmology, Toronto Western Hospital, Department of Ophthalmology and Vision Sciences, University of Toronto, Toronto, Canada

Correspondence to:

Mr S Srinivasan, Department of Ophthalmology, Ayr Hospital,

Dalmellington Road,

Ayr KA6 6DX, UK;

sathish.srinivasan@gmail.com

Presented in part at the American Academy of Ophthalmology Annual Meeting,

Las Vegas, November, 2006.

Accepted 26 October 2008

Published Online First

19 November 2008

\title{
Fibrin glue versus sutures for attaching the conjunctival autograft in pterygium surgery: a prospective observer masked clinical trial
}

\author{
S Srinivasan, M Dollin, P McAllum, Y Berger, D S Rootman, A R Slomovic
}

\begin{abstract}
Aims: To compare the degree of conjunctival autograft inflammation, subconjunctival haemorrhage (SCH) and graft stability following the use of sutures or fibrin glue (FG) during pterygium surgery.
\end{abstract}

Methods: Prospective, observer masked, clinical trial. 40 eyes of 40 patients undergoing primary pterygium surgery with conjunctival autograft were allocated into two groups. Group $1(n=20)$ had FG (Tisseel) for attaching the conjunctival autograft, whereas group $2(n=20)$ had sutures. Standardised digital slit-lamp photographs were taken at 1 week, 1 month and 3 months postoperatively. Sutures were masked using commercially available photoediting software. Two masked observers objectively graded the digital photographs for degree of inflammation, SCH and graft stability.

Results: 34 of the 40 patients completed the study. When using FG, the degree of inflammation was significantly less than with sutures at 1 month $(p=0.019)$ and 3 months $(p=0.001)$ postoperatively. No significant difference was found for inflammation at 1 week postoperatively $(p=0.518)$. Conjunctival grafts secured with FG were as stable as those secured with sutures $(p=0.258, p=0.076$ and $p=0.624$, at 1 week, 1 month and 3 months, respectively). No significant difference was found in degree of postoperative $\mathrm{SCH}$ between the groups $(p=0.417, p=1$ and $p=1$, at 1 week, 1 month and 3 months, respectively).

Conclusion: This is the first prospective clinical trial confirming that conjunctival grafts secured with FG during pterygium surgery not only are as stable as those secured with sutures, but also produce significantly less inflammation.

The prevalence rate of primary pterygium varies from 0.7 to $31 \%$ in various populations around the world. ${ }^{2}$ Recent immunohistochemical studies support the theory that p53-mutated limbal epithelial basal stem cells lead to the development of pterygium. ${ }^{3}$ Several surgical techniques have been described for its management. ${ }^{4}$ Kenyon et al introduced the surgical technique of using conjunctival autograft in the management of primary advanced and recurrent pterygium. ${ }^{5}$ Although more time-consuming, this technique was found to be safe and effective in reducing the number of recurrences while avoiding the risk of potentially serious complications. ${ }^{67}$ A meta-analysis on the surgical techniques for pterygium excision showed that the odds for pterygium recurrence following surgical treatment of primary pterygium are close to six and 25 times higher if no conjunctival autograft placement is performed. ${ }^{8}$
Traditionally, during pterygium surgery the conjunctival autografts are secured in place with either absorbable or non-absorbable sutures. Tisseel (Tisseel, Baxter Corporation, Mississauga, Canada) is a two-component tissue adhesive which mimics the natural fibrin formation. It has been used in neurosurgery, plastic surgery, ear, nose and throat surgery, and ocular surgery. The use of fibrin glue (FG) during pterygium surgery was first described by Cohen et al in $1993 .{ }^{10}$ Since then there have been several reports on the safety and efficacy of FG during pterygium surgery. ${ }^{11-13}$

A recent retrospective study on a large cohort suggested that pterygium surgery with FG leads to significantly lower recurrence rate when compared with the use of sutures. ${ }^{14}$

Although it is conceptualised that pterygium surgery with FG produces less postoperative inflammation when compared with sutures, ${ }^{14}$ to the best of our knowledge, based on a Medline search, there has been no prospective clinical study demonstrating this. We performed a prospective, observer masked clinical trial to compare the degree of conjunctival graft inflammation, subconjunctival haemorrhage $(\mathrm{SCH})$ and graft stability following the use of sutures or FG for attaching the conjunctival autograft during pterygium surgery.

\section{MATERIALS AND METHODS}

\section{Study population}

Between October 2005 and January 2006, from a continuous cohort of 55 patients with primary pterygium referred to the Corneal Service at the Toronto Western Hospital, Toronto, 40 subjects were recruited to undergo primary pterygium excision with conjunctival autograft using FG or 10-0 polyglactin (vicryl) sutures. Institutional review board approval was obtained through the Toronto Academic Health Sciences Network/ University Health Network Research Ethics Board, Toronto, Canada. The surgical procedures complied with the tenets of the Declaration of Helsinki. Inclusion criteria were a primary nasal pterygium, for which surgery was recommended, and willingness to participate in the clinical study. Exclusion criteria were subjects on anticoagulants, and recurrent or temporal location of pterygium. All patients gave written informed consent to participate in the study.

\section{Surgical procedure}

The surgical procedures were performed by two surgeons (SS and PM). The surgical procedures for subjects in group 1 (FG group, $\mathrm{n}=20$ ) were 
Table 1 Scoring parameters for each of the three outcome variables

\begin{tabular}{ll}
\hline Outcome variables & Scoring parameters \\
\hline Subconjunctival haemorrhage & Grade 0: None \\
& Grade 1: $\leqslant 25 \%$ of the size of the graft \\
& Grade 2: $\leqslant 50 \%$ of the size of the graft \\
& Grade 3: $\leqslant 75 \%$ of the size of the graft \\
& Grade 4: Haemorrhage involving the entire graft (no subconjunctival vessels visible) \\
& Grade 0: No dilated corkscrew vessel in the graft \\
& Grade 1: 1 bright red, dilated corkscrew vessel crossing the graft-bed margin \\
Inflammation & Grade 2: 2 bright red, dilated corkscrew vessels crossing the graft-bed margin \\
& Grade 3: three bright red, dilated corkscrew vessels crossing the graft-bed margin \\
& Grade 4: $\geqslant 3$ bright red, dilated corkscrew vessels crossing the graft-bed margin \\
& Grade 0: All four sides of the graft margin are well apposed \\
& Grade 1: Gaping/displacement of one side of the graft-bed junction \\
& Grade 2: Gaping/displacement of two sides of the graft-bed junction \\
& Grade 3: Gaping/displacement of three sides of the graft-bed junction \\
& Grade 4: Graft completely displaced from the bed \\
\hline
\end{tabular}



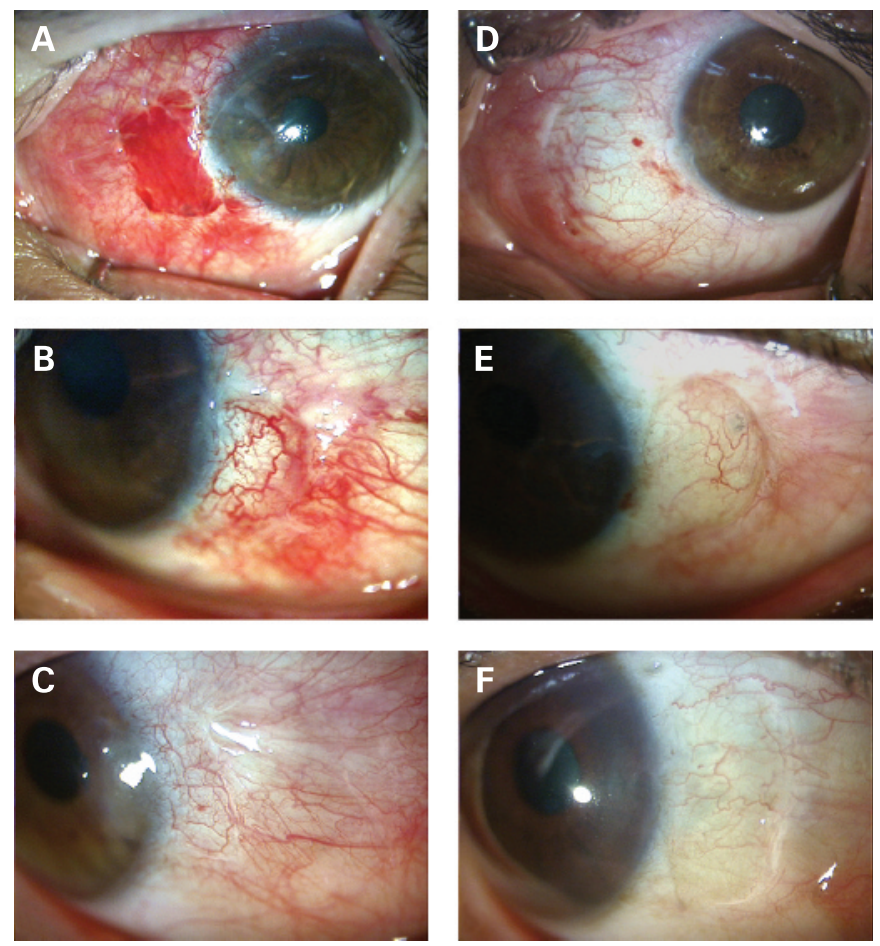

Figure 1 (A-C) Standardised slit-lamp photographs taken at 1 week, 1 month, and 3 months, respectively, following pterygium surgery with conjunctival autograft using sutures. Note that the sutures have been masked in these pictures using a software program. (D-F) Standardised slit-lamp photographs taken at 1 week, 1 month, and 3 months, respectively, following pterygium surgery with conjunctival autograft using fibrin glue.

into a PowerPoint program (Microsoft Office 2003, Microsoft Corporation, Redmond, Washington). Two independent observers (DSR and ARS), who were completely masked to the editing and slide insertion protocol, reviewed the digital PowerPoint slides and graded each picture on the degree of graft inflammation, SCH and stability. The outcome variables and the scoring scale are summarised in table 1.

\section{Statistical analysis}

Statistical analysis was performed using SPSS 13.0 (SPSS, Chicago). Outcome variables between the two groups were compared using the non-parametric Mann-Whitney U Test. The conventional level of significance $\mathrm{p}<0.05$ was applied in all cases.

\section{RESULTS}

The cohort consisted of 17 (42\%) males. The mean age was 47 years (range 32 to 72). Thirty-four of the 40 patients completed the 3 months' follow-up. The results are summarised in table 2 .

The degree of inflammation was significantly less in the FG group at both 1 month $(p=0.019)$ and 3 months $(p=0.001)$ postoperatively (fig 1 ). There was no significant difference in the degree of inflammation between the groups at 1 week postoperatively $(p=0.518)$. Conjunctival graft stability with FG was the same as with sutures over the 3 months' course of follow-up ( $p=0.258, p=0.076$ and $p=0.624$, at 1 week, 1 month and 3 months, respectively). There was no significant difference in the degree of SCH between the groups at any point during the follow-up period $(p=0.417, p=1$ and $p=1$, at 1 week, 1 month and 3 months, respectively).

\section{DISCUSSION}

Pterygium recurrence is the most common complication of pterygium surgery and is a frequent source of frustration for patients and surgeons. With the aim of reducing recurrence rates, several surgical techniques have been described in the literature. These include bare sclera excision, ${ }^{15}$ conjunctival and conjunctival-limbal autograft, ${ }^{516}$ and the use of amniotic membrane. ${ }^{17}$ In addition, several adjunctive therapies, including the use of beta irradiation ${ }^{18}$ and mitomycin C (MMC), ${ }^{19}$ have been recommended due to their anti-fibrotic and anti-angiogenic properties.

From 1960 to the early 1980s, bare sclera closure was the most popular method for surgical removal of a primary pterygium. ${ }^{4}$ However, it has been shown that it is by far the least satisfactory method with respect to recurrence rates, which can be as high as $80 \% .{ }^{4}$ The use of conjunctival autograft gained popularity in the 1980s following the landmark article by Kenyon et al in $1985 .{ }^{5}$ He reported a low recurrence rate of $5.3 \%$ using the conjunctival autograft technique. Since his publication, other prospective, randomised studies of conjunctival autografting during pterygium surgery have reported higher recurrence rates (16-39\%) in high-risk populations. ${ }^{19}{ }^{20}$ Nonetheless, a recent detailed review on the treatment of pterygium concluded that conjunctival autograft remains the safest technique and offers the lowest rate of recurrence in the management of primary pterygium. ${ }^{4}$

There is evidence that UV light-induced limbal stem-cell damage can act as precursor to the development of pinguecula and pterygium. ${ }^{21}$ Thus, conceptually, one could possibly reduce pterygium recurrence rates by including the limbus in the harvested conjunctival autograft. Conjunctival-limbal autograft has been shown to be effective in the management of both primary and recurrent pterygia. ${ }^{22}$ There is very little scientific data on the preoperative morphological appearance, epidemiological status or surgical factors that influence pterygium recurrence rate. Tan et al in a prospective study were able to demonstrate that fleshiness of the pterygium is a significant risk factor for recurrence if bare sclera excision is performed. ${ }^{23}$

Tisseel is a commercially available two-component fibrin sealant which mimics the natural fibrin and acts as tissue glue with sealing, haemostatic and gluing properties. The glue has two components: (1) sealant protein, a freeze-dried powder composed of human fibrinogen, fibrinonectin, plasminogen and Factor XIII reconstituted in a bovine aprotinin solution; (2) sealant setting, a solution composed of human thrombin reconstituted in a calcium chloride solution. When both of these solutions interact, through the action of thrombin, the fibrinopeptides are broken down to fibrin monomers. These monomers aggregate by cross-linking, leading to the formation of fibrin clot. Use of FG during pterygium surgery not only is safe and effective ${ }^{11-14}$ but also produces less postoperative pain when compared with the use of sutures. ${ }^{11}$

$\mathrm{Ti}$ and Tseng demonstrated that increased inflammation during the postoperative period increases the risk of pterygium recurrence. ${ }^{24}$ Zuzuki et al showed that the use of silk and nylon sutures placed in the conjunctiva can cause inflammation, and migration of Langerhans' cells to the cornea. ${ }^{25}$ In a large retrospective study, Koranyi et al were able to demonstrate a statistically significant decreased recurrence rate with the use of FG when compared with the use of sutures. ${ }^{14}$ They postulated that a possible reduction in the migration of fibroblast cells 
caused by the rapid adhesion of the graft with the FG may lead to decreased postoperative inflammation.

In our prospective, photo-documented, observer-masked clinical trial, we were able to demonstrate decreased postoperative inflammation (at both a 1-month and 3-month time gate) with the use of FG compared with polyglactin sutures. Although the aetiopathogenesis of pterygium recurrence may be multifactorial, we believe that reducing postoperative inflammation may play a significant role in reducing the recurrence rate. ${ }^{24}$ Larger, prospective studies are required to evaluate the long-term efficacy on the use of FG in reducing the recurrence rate.

Competing interests: None.

Ethics approval: Ethics approval was provided by the Toronto Academic Health Sciences Network/University Health Network Research Ethics Board, Toronto, Canada.

Patient consent: Obtained.

\section{REFERENCES}

1. Detels R, Dhir SP. Pterygium: a geographical survey. Arch Ophthalmol 1967;78:485.

2. Sivasubramaniam P. Pterygium in Ceylon. Br J Ophthalmol 1971;55:55

3. Chowers I, Pe'er J, Zamir $\mathrm{E}$, et al. Proliferate activity and $\mathrm{p} 53$ expression in primary and recurrent pterygium. Ophthalmology 2001;108:985-8.

4. Hirst LW. The treatment of pterygium. Surv Ophthalmol 2003;48:145-80.

5. Kenyon KR, Wagoner MD, Hettinger ME. Conjunctival autograft transplantation for advanced and recurrent pterygium. Ophthalmology 1985;92:1461-70.

6. Starck T, Kenyon KR, Serrano F. Conjunctival autograft for primary and recurrent pterygia: surgical technique and problem management. Cornea 1991;10:196-202.

7. Allan BDS, Short P, Crawford GJ, et al. Pterygium excision with conjunctival autografting: an effective and safe technique. Br J Ophthalmol 1993:77:698-701.

8. Sanchez-Thorin JC, Rocha G, Yelin JB. Meta-analysis on the recurrence rates after bare sclera resection with and without mitomycin $\mathrm{C}$ use and conjunctival autograft placement in surgery for primary pterygium. Br J Ophthalmol 1998:82:661-5.
9. Schlag G, Aschler PW, Steinkogler FJ, et al. Fibrin sealing in surgical and nonsurgical fields, Vol. 5. Neurosurgery, ophthalmic surgery, ENT. Berlin: Springer Verlag, 1994.

10. Cohen RA, McDonald MB. Fixation of conjunctival autografts with an organic tissue adhesive [letter]. Arch Ophthalmol 1993:111:1167-8.

11. Koranyi G, Seregard S, Kopp ED. Cut and paste: a no suture, small incision approach to pterygium surgery. Br J Ophthalmol 2004;88:911-14.

12. Uy HS, Reyes JM, Flores JD, et al. Comparison of fibrin glue and sutures for attaching conjunctival autografts after pterygium excision. Ophthalmology 2005; 112:667-71.

13. Marticorena J, Rodriguez-Ares MT, Tourino R, et al. Pterygium surgery: Conjunctival autograft using a fibrin adhesive. Cornea 2006;25:34-6.

14. Koranyi G, Seregard S, Kopp ED. The cut-and-paste method for primary pterygium surgery: long-term follow up. Acta Ophthalmol Scand 2005;83:298-301.

15. Adamis AP, Starck T, Kenyon KR. The management of pterygium. Ophthalmol Clin North Am 1990;3:611-23.

16. Kenyon KR, Tseng SC. Limbal autograft transplantation for ocular surface disorders. Ophthalmology 1989;96:709-23.

17. Prabhasawat P, Barton K, Burkett G, et al. Comparison of conjunctival autografts amniotic membrane grafts and primary closure for pterygium excision. Ophthalmology 1997; 104:974-85.

18. Mackenzie FD, Hirst LW. Recurrence rate and complications after beta irradiation for pterygia. Ophthalmology 1991:98:1776-81.

19. Manning CA, Loess PM, Diaz MD, et al. Intraoperative mitomycin in primary pterygium excision. Ophthalmology 1997;104:844-8.

20. Mahar PS. Conjunctival autograft versus topical mitomycin $\mathrm{C}$ in the treatment of pterygium. Eye 1997;11:790-2

21. Dushku N, John MK, Schultz GS, et al. Pterygia pathogenesis: corneal invasion by matrix metalloproteinase expressing altered limbal epithelial basal cells. Arch Ophthalmol 2001;119:695-706

22. Al Fayez MF. Limbal versus conjunctival autograft transplantation for advanced and recurrent pterygium. Ophthalmology 2002;109:1752-5.

23. Tan DT, Chee SP, Dear KB, et al. Effect of pterygium morphology on pterygium recurrence in a controlled trial comparing conjunctival autografting with bare sclera excision. Arch Ophthalmol 1997;115:1235-40.

24. Ti SE, Tseng SC. Management of primary and recurrent pterygium using amniotic membrane transplantation. Curr Opin Ophthalmol 2002;13:204-12.

25. Suzuki T, Sano Y, Kinoshita S. Conjunctival inflammation induces Langerhans' cell migration into the cornea. Curr Eye Res 2000;21:550-3. 